\title{
Surgical approaches and outcomes for cervical myelopathy with increased signal intensity on T2-weighted MRI: a meta-analysis
}

\author{
Xu Yuan ${ }^{1 \dagger}$, Chen Feng ${ }^{2+}$, Wang Yipeng ${ }^{2}$, Zhang Jianguo ${ }^{2}$ and Hu Jianhua ${ }^{2 *}$
}

\begin{abstract}
Objective: Increased signal intensity (ISI) on T2-weighted magnetic resonance imaging (MRI) often indicates severe compression in patients with cervical myelopathy (CM). The optimal surgical approach for CM patients with ISI on T2-weighted MRI remains unclear. This meta-analysis aims to compare the clinical outcomes between anterior and posterior approaches for the treatment of these patients.

Methods: MEDLINE, EMBASE, Web of Science, and Chinese National Knowledge Infrastructure (CNKI) were searched for relevant studies through January 2019. Statistical comparisons were made when appropriate.

Results: A total of 9 studies (748 participants) out of 1066 citations were included in this study. All of the selected studies were high quality, as indicated by the Newcastle-Ottawa scale and the Cochrane Collaboration tool for assessing the risk of bias. Clinical outcomes were compared between anterior and posterior approaches in 4 studies (237 participants). The preoperative Japanese Orthopedic Association (JOA) score was similar between the two groups $[P=0.98$, weighted mean difference $(W M D)=0.01(-0.58,0.59)]$. The postoperative JOA score $[P<0.05$, $W M D=0.68(0.06,1.30)]$ and recovery rates $[P<0.01, W M D=0.12(0.06,0.17)]$ were significantly higher in the anterior group than in the posterior group.
\end{abstract}

Conclusion: The anterior approach was associated with better postoperative neural function than the posterior approach in CM patients with ISI on T2-weighted MRI.

\section{Introduction}

Cervical myelopathy $(\mathrm{CM})$ is a common cause of progressive spinal cord dysfunction. The most common etiology for $\mathrm{CM}$ is spinal stenosis caused by cervical spondylosis and ossification of the posterior longitudinal ligament (OPLL) [1]. Surgical treatment aims to expand the cervical canal and relieve the compression of the spinal cord. There are two main surgical approaches: the anterior approach and the posterior approach. Anterior approaches, which can achieve direct decompression by directly removing the ventral stenosing focus, typically

\footnotetext{
*Correspondence: pumch_hujianhua@163.com

${ }^{\dagger}$ Yuan Xu and Feng Chen are co-first authors.

${ }^{2}$ Department of Orthopedics, Peking Union Medical College Hospital, Chinese Academy of Medical Science \& Peking Union Medical College, Beijing, China

Full list of author information is available at the end of the article
}

comprise anterior cervical discectomy and fusion (ACDF) and anterior cervical corpectomy decompression and fusion (ACCF). Posterior approaches, which can achieve indirect decompression by shifting the spinal cord posteriorly, typically comprise laminoplasty or laminectomy. The choice of the surgical approach for $\mathrm{CM}$ has been a controversial issue. Several recent metaanalyses concluded that the anterior approach is associated with better postoperative neurological outcomes than the posterior approach [2-4].

Magnetic resonance imaging (MRI) of the cervical spine is widely used in the diagnosis and preoperative evaluation of CM [5]. Although increased signal intensity (ISI) on T2-weighted MRI often indicates more severe compression, its prognostic value has been debated in several articles with conflicting results, and the optimal surgical approach for these patients remains unclear.

(c) The Author(s). 2019 Open Access This article is distributed under the terms of the Creative Commons Attribution 4.0 International License (http://creativecommons.org/licenses/by/4.0/), which permits unrestricted use, distribution, and reproduction in any medium, provided you give appropriate credit to the original author(s) and the source, provide a link to the Creative Commons license, and indicate if changes were made. The Creative Commons Public Domain Dedication waiver (http://creativecommons.org/publicdomain/zero/1.0/) applies to the data made available in this article, unless otherwise stated. 
The purpose of this study was to perform a metaanalysis of surgical approaches for the treatment of patients with CM with ISI on T2-weighted MRI and to specifically evaluate the clinical results to guide clinical decision-making.

\section{Methods}

\section{Inclusion and exclusion criteria}

Studies were included if they met the following inclusion criteria: (1) the study was a randomized or nonrandomized controlled study (for prospective studies) or a retrospective study, (2) patients were diagnosed with CM due to cervical spondylotic myelopathy (CSM) or OPLL, (3) patients underwent surgical treatment, (4) comparative data between anterior and posterior approaches (regardless of the specific surgical approach) were available, (5) T2 ISI information was available for all or subgroups of patients, and (6) the study had an average follow-up time of $\geq 12$ months. Studies were excluded if (1) patients were diagnosed with CM resulting from another etiology, such as trauma, a tumor, or rheumatoid arthritis; (2) patients underwent related thoracic or lumbar surgeries; or (3) the full text could not be accessed.

\section{Search strategy}

MEDLINE, EMBASE, Web of Science, and Chinese National Knowledge Infrastructure (CNKI) were searched through January 2019. The search was not restricted to any specific language or by the year of publication. The following search terms and strategies were used: (1) CM OR CSM OR myelopathy OR cervical spondylosis OR cervical vertebrae OR cervical stenosis OR OPLL OR ossification of posterior longitudinal ligament, (2) corpectomy OR ACDF OR ACCF OR anterior cervical corpectomy decompression and fusion OR anterior cervical discectomy and fusion OR anterior decompression OR ventral decompression OR ventral approach, (3) laminoplasty OR laminectomy OR posterior decompression OR posterior decompression and fusion OR dorsal decompression OR dorsal approach, (4) MRI OR T2 OR T2WI OR signal intensity OR magnetic resonance imaging, and (1) and (2) and (3) and (4). Data were extracted with a standardized form [6]. The Newcastle-Ottawa Scale (NOS) was used for quality assessment of nonrandomized studies [7], and the Cochrane Collaboration tool for assessing risk of bias [8] was used for randomized studies. Two reviewers independently reviewed the articles in the initial and full-text reviews. Any disagreement between reviewers was resolved by discussion with a third reviewer.

\section{Statistical analysis}

Inconsistency between studies was quantified by calculating the $I^{2}$ statistic. Continuous variables are reported as weighted mean differences (WMDs) and 95\% confidence intervals (95\% CIs), whereas dichotomous variables are presented as odds ratios (ORs) and 95\% CIs. A randomeffects model was used for heterogeneous data $\left(I^{2}>50 \%\right)$, whereas a fixed-effects model was used for homogenous data $\left(I^{2}<50 \%\right)$. For studies presenting data as medians and quartiles, the mean and standard deviation (SD) were calculated by methods described by Hozo et al. [9]. $P<0.05$ was considered to be statistically significant. SAS software, version 9.1 (SAS Institute, Cary, NC, USA), and Review Manager, version 5.1 (The Cochrane Collaboration), were used to perform statistical analysis.

\section{Results}

\section{Search results}

The initial database search identified 793 articles in MEDLINE, 619 in EMBASE, 840 in Web of Science, and 9 in CNKI. After excluding duplicate records, there were 1066 studies. A total of 1015 articles were excluded because they failed to meet the inclusion criteria after review of the abstracts and titles. An additional 42 articles were excluded after the full-text review. Hence, a total of 9 studies were finally selected, including 1 prospective randomized study, 6 prospective nonrandomized studies, and 2 retrospective studies. The detailed selection process is shown in Fig. 1.

\section{Quality assessment}

The basic characteristics of the included studies are shown in Table 1. The quality of the included nonrandomized studies was assessed using the NOS (http:// www.ohri.ca/programs/clinical_epidemiology/oxford.htm). Two independent reviewers conducted the assessment. Disagreements were resolved by discussion. Of the nonrandomized studies, four scored 8 points, two scored 7 points, and two scored 6 points (Table 2). The Cochrane Collaboration tool for assessing risk of bias was used to assess the randomized study (one study), as shown in Figure S1. The assessments indicated that all of the studies were of relatively high quality.

\section{Surgical approaches}

The 9 studies included a total of 748 patients with ISI on T2-weighted MRI. Data on the surgical approach were extracted for 505 patients, among whom 223 underwent an anterior approach, including ACCF, ACDF, anterior cervical disc replacement (ACDR), or hybrid anterior decompression and fusion (HDF), and 282 underwent a posterior approach, including laminoplasty or laminectomy.

\section{Clinical outcomes}

The Japanese Orthopedic Association (JOA) score was available in 4 studies to assess the clinical outcome $(n=$ 237 patients; 78 in the anterior group and 159 in the 


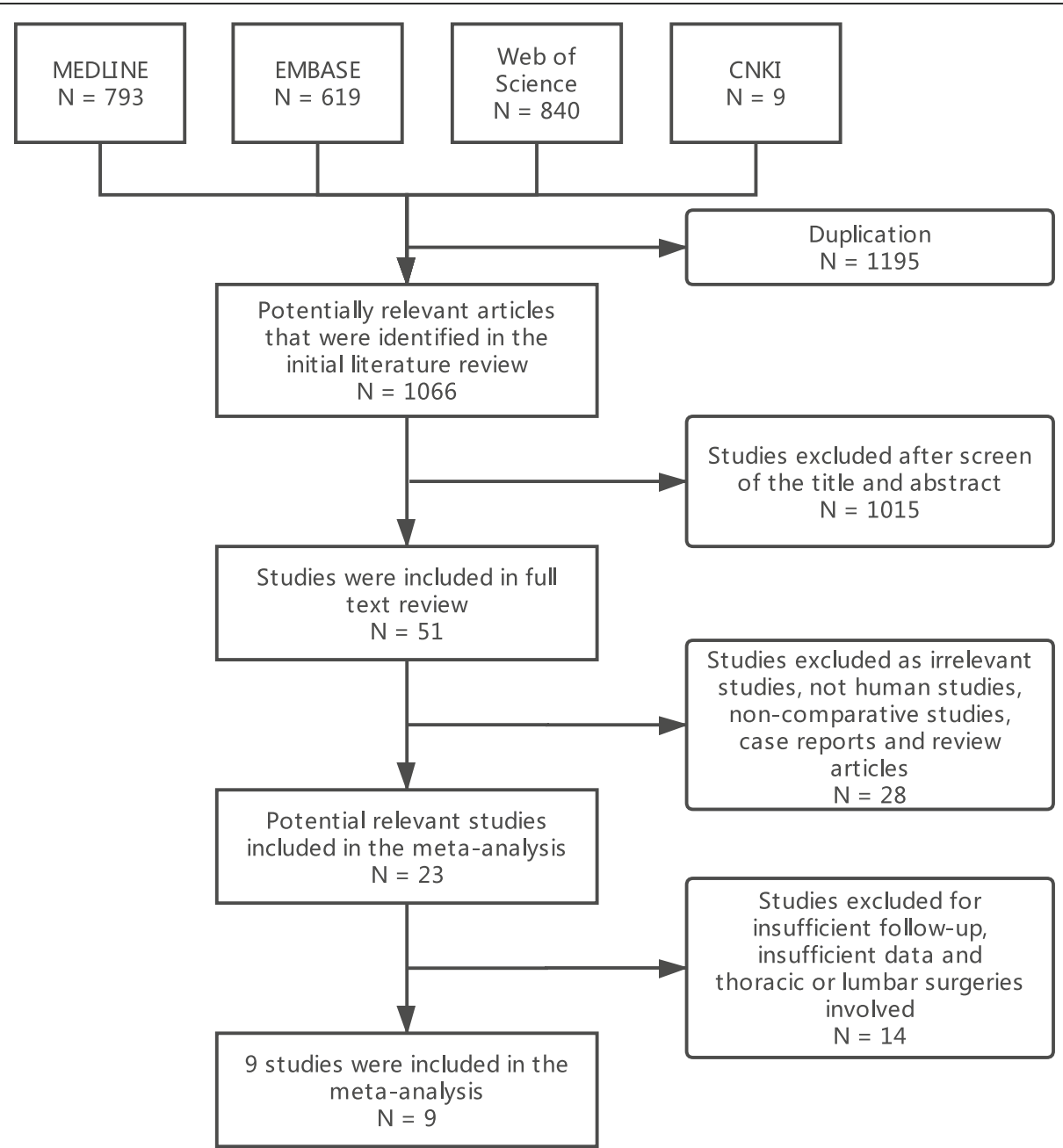

Fig. 1 A flow diagram of study selection

posterior group). The preoperative JOA score was similar between the two groups $[P=0.98$, WMD $=0.01 \quad(-$ $0.58,0.59)$; heterogeneity: $X^{2}=1.33, \mathrm{df}=3, P=0.72 ; I^{2}=$ $0 \%$, fixed-effects model; Fig. 2]. The postoperative JOA score was significantly higher in the anterior group than in the posterior group $[P<0.05, W M D=0.68(0.06$, 1.30); heterogeneity: $X^{2}=2.76, \mathrm{df}=3, P=0.43 ; I^{2}=0 \%$, fixed-effects model; Fig. 3]. The recovery rate, as defined by Hirabayashi's formula: (postoperative JOA scorepreoperative JOA score $) /(17$ - preoperative JOA score $) \times$ $100 \%$, was used to assess the surgical outcome. Similar to the results of the postoperative JOA score, the recovery rate was significantly higher in the anterior group than in the posterior group $[P<0.01, \mathrm{WMD}=0.12(0.06,0.17)$; heterogeneity: $X^{2}=3.59, \mathrm{df}=3, P=0.31 ; I^{2}=17 \%$, fixedeffects model; Fig. 4]. Data regarding complications were scarce. Only Sun's study reported that the anterior approach was associated with more blood loss and a longer operative time [11].

\section{Discussion}

In the present study, we searched MEDLINE, EMBASE, Web of Science, and CNKI. We compared surgical outcomes of anterior and posterior surgical approaches in CM patients with ISI on T2-weighted MRI. We showed that the anterior approach was associated with better recovery than the posterior approach, as assessed by the JOA score.

$\mathrm{CM}$ is a common cause of spinal cord dysfunction in older persons. Since Takahashi first reported ISI on T2weighted MRI in a patient with CM [19], MRI has been recognized as essential for the diagnosis and treatment of CM. It is documented that $41-97 \%$ of patients with CM have ISI on T2-weighted MRI within the cervical cord [20]. The role of signal intensity changes on MRI has been widely investigated. There are several theories explaining ISI on T2-weighted MRI: (1) myelomalacia caused by spinal edema or chronic spinal cord compression, (2) destruction of the local cerebrospinal fluid 
Table 1 Basic characteristics of the included studies

\begin{tabular}{|c|c|c|c|c|c|c|c|c|c|c|}
\hline $\mathrm{ID}$ & Location & Design & $\begin{array}{l}\text { Enrollment } \\
\text { years }\end{array}$ & $\begin{array}{l}\text { No. with } \\
\text { T2 IS| }\end{array}$ & $\begin{array}{l}\text { Classification } \\
\text { of T2 ISI }\end{array}$ & $\begin{array}{l}\text { Follow-up } \\
\text { time (month) }\end{array}$ & Diagnosis & Segments & $\begin{array}{l}\text { Surgical } \\
\text { approach }\end{array}$ & $\begin{array}{l}\text { No. using } \\
\text { approach }\end{array}$ \\
\hline \multirow{2}{*}{$\begin{array}{l}\mathrm{Gu} \\
\text { et al. [10] }\end{array}$} & \multirow[t]{2}{*}{ China } & \multirow{2}{*}{$\begin{array}{l}\text { Prospective } \\
\text { nonrandomized } \\
\text { controlled }\end{array}$} & \multirow[t]{2}{*}{ 2010-2012 } & \multirow[t]{2}{*}{140} & \multirow[t]{2}{*}{ NM } & \multirow[t]{2}{*}{$27(12-360)$} & \multirow[t]{2}{*}{ OPLL } & \multirow[t]{2}{*}{$2-6$} & A: ACCF & 27 \\
\hline & & & & & & & & & $\begin{array}{l}\text { P: Laminectomy, } \\
\text { Laminoplasty }\end{array}$ & 113 \\
\hline \multirow{2}{*}{$\begin{array}{l}\text { Sun } \\
\text { et al. [11] }\end{array}$} & \multirow[t]{2}{*}{ China } & \multirow{2}{*}{$\begin{array}{l}\text { Prospective } \\
\text { randomized } \\
\text { controlled }\end{array}$} & \multirow[t]{2}{*}{ 2005-2008 } & \multirow[t]{2}{*}{31} & \multirow[t]{2}{*}{ NM } & \multirow[t]{2}{*}{$20.3(12-34)$} & \multirow[t]{2}{*}{ OPLL } & \multirow[t]{2}{*}{ NM } & A (NM) & 15 \\
\hline & & & & & & & & & P: Laminoplasty & 16 \\
\hline \multirow{2}{*}{$\begin{array}{l}\text { Liu } \\
\text { et al. [12] }\end{array}$} & \multirow[t]{2}{*}{ China } & \multirow{2}{*}{$\begin{array}{l}\text { Prospective } \\
\text { nonrandomized } \\
\text { controlled }\end{array}$} & \multirow[t]{2}{*}{$2002-2006$} & \multirow[t]{2}{*}{17} & \multirow[t]{2}{*}{ NM } & \multirow[t]{2}{*}{$81.6(60-120)$} & \multirow[t]{2}{*}{ OPLL } & \multirow[t]{2}{*}{ NM } & A: ACCF & 7 \\
\hline & & & & & & & & & P: Laminoplasty & 10 \\
\hline \multirow[t]{2}{*}{ Wang [13] } & \multirow[t]{2}{*}{ China } & \multirow{2}{*}{$\begin{array}{l}\text { Prospective } \\
\text { nonrandomized } \\
\text { controlled }\end{array}$} & \multirow[t]{2}{*}{ 2000-2007 } & \multirow[t]{2}{*}{49} & \multirow[t]{2}{*}{ Qualitative } & \multirow[t]{2}{*}{$13.8(12-60)$} & CSM & NM & $A: A C C F$ & 29 \\
\hline & & & & & & & & & P: Laminoplasty & 20 \\
\hline $\begin{array}{l}\text { Yang } \\
\text { et al. [14] }\end{array}$ & China & $\begin{array}{l}\text { Prospective } \\
\text { nonrandomized }\end{array}$ & 2010-2014 & 202 & NM & $36(28-40)$ & OPLL & $\geq 2$ & $\begin{array}{l}\text { A:ACCF, ACDF, } \\
\text { HDF }\end{array}$ & 121 \\
\hline & & controlled & & & & & & & P: Laminoplasty & 81 \\
\hline $\begin{array}{l}\text { Salem } \\
\text { et al. [15] }\end{array}$ & The UK & $\begin{array}{l}\text { Prospective } \\
\text { nonrandomized }\end{array}$ & 2006-2010 & 66 & NM & $37(17-88)$ & CSM & NM & $\begin{array}{l}\text { A:ACCF, ACDF, } \\
\text { ACDR }\end{array}$ & 24 \\
\hline & & & & & & & & & P: Laminoplasty & 42 \\
\hline Suri & India & Prospective & 1999-2001 & 121 & NM & $12-24$ & CSM & $\geq 1$ & $\mathrm{~A}: \mathrm{ACCF}, \mathrm{ACDF}$ & NM \\
\hline 6] & & $\begin{array}{l}\text { nonrandomized } \\
\text { controlled }\end{array}$ & & & & & & & $\begin{array}{l}\text { P: Laminectomy, } \\
\text { Laminoplasty }\end{array}$ & \\
\hline Tauchi & Japan & Retrospective & $1991-2010$ & 21 & NM & $32.4(12-153)$ & CSM & NM & $A: A C C F, A C D F, H D F$ & NM \\
\hline & & & & & & & & & $\begin{array}{l}\text { P: Laminectomy, } \\
\text { Laminoplasty }\end{array}$ & \\
\hline Uchida & Japan & Retrospective & 1988-2001 & 101 & Qualitative & $99.6(12-154)$ & CSM, OPLL & $\geq 1$ & $\mathrm{~A}: \mathrm{ACCF}, \mathrm{ACDF}$ & NM \\
\hline & & & & & & & & & P: Laminoplasty & \\
\hline
\end{tabular}

$N M$, not mentioned

(CSF) barrier, (3) obstruction of the flow of CSF, and (4) degeneration of gray matter at the level of compression level $[21,22]$. Several studies have suggested that cervical instability is a risk factor for ISI on T2-weighted MRI because dynamic factors may result in spinal cord injury [23-25]. Moreover, Yagi et al. suggested that males were more likely to have ISI on T2-weighted MRI than females $(\mathrm{OR}=3.348)$, although the difference was not significant $(P=0.101)$ [26]. This finding may result

Table 2 Quality assessment according to the NewcastleOttawa scale

\begin{tabular}{lllll}
\hline ID & Selection & Comparability & Exposure & Total score \\
\hline Gu et al. [10] & 3 & 2 & 3 & 8 \\
Liu et al. [12] & 3 & 2 & 3 & 8 \\
Wang [13] & 2 & 2 & 3 & 7 \\
Yang et al. [14] & 3 & 1 & 3 & 7 \\
Salem et al. [15] & 2 & 1 & 3 & 6 \\
Suri et al. [16] & 3 & 2 & 3 & 8 \\
Tauchi et al. [17] & 2 & 1 & 3 & 6 \\
Uchida et al. [18] & 3 & 2 & 3 & 8 \\
\hline
\end{tabular}

from the higher morbidity of developmental cervical spinal canal stenosis in males than in females.

Several studies have suggested that patients with ISI have poor clinical results after either conservative or surgical treatment. However, some other studies have challenged this hypothesis [27]. To clarify this question, several studies have classified signal intensity changes via different methods and studied their relevance to clinical outcomes. Aditya et al. categorized the various classification methods into two major types: the longitudinal extent of ISI and qualitative classification of ISI [20]. Studies using the longitudinal extent to classify ISI have usually suggested that patients with multisegmental ISI have more severely compressed cords [28], poorer surgical outcomes [29], and worse recovery rates [30] than those with focal or absent ISI. The qualitative classification of ISI involves an assessment of the intensity, marginal pattern, or both. Studies using qualitative classification are controversial. Most studies have indicated that sharp, more intense ISI is correlated with worse clinical outcomes [31-35], whereas other studies have suggested that the intensity of ISI on T2-weighted images does not predict surgical outcomes $[27,36]$. 


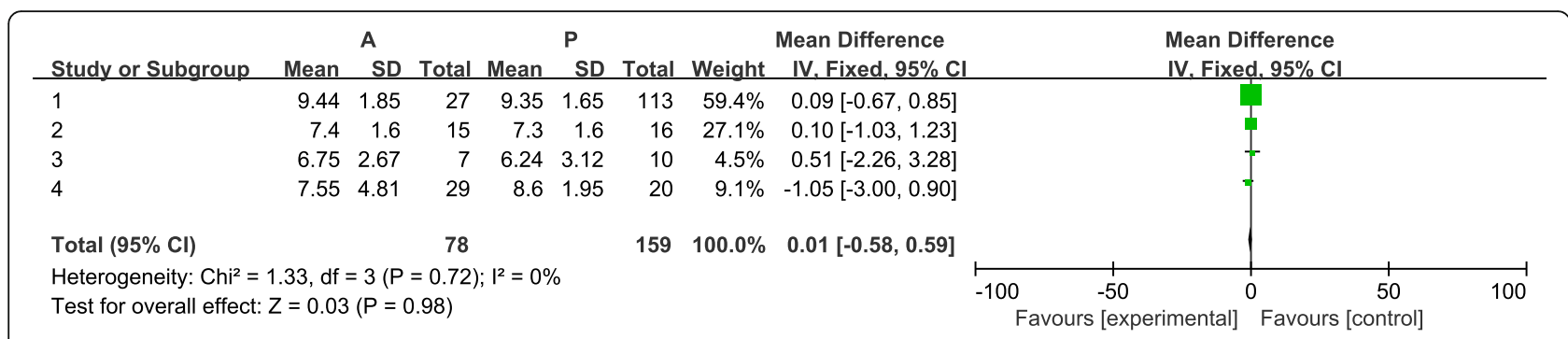

Fig. 2 Weighted mean difference in the preoperative JOA score between the anterior surgery group and the posterior surgery group

As there are usually multiple sources of compression from the anterior and/or posterior sides, several factors should be taken into consideration when choosing the approach. MRI findings play an important role in decision-making. Nouri et al. conducted a questionnaire survey among 513 AOSpine International members to understand how specific pathologic features on MRI influence the surgeon's selection of a surgical approach selection in patients with degenerative CM [37]. Multilevel bulging disks, cervical kyphosis, and a high degree of anterior cord compression have been reported to lead to selection of an anterior approach, whereas a high degree of posterior cord compression, multilevel compression, OPLL, ligamentum flavum enlargement, and congenital stenosis have been reported to lead to selection of a posterior approach [2, 3, 37]. Although the presence of ISI on T2-weighted MRI is not considered an important factor that influences decision-making, interviewers were slightly more likely to choose the anterior approach than the posterior approach ( $23.4 \%$ vs. $15.6 \%$, respectively).

In the present study, the postoperative JOA scores and recovery rates were significantly higher following the anterior approach than following the posterior approach, suggesting that the neurological outcomes were better with the anterior approach. Although there have been no meta-analyses or systemic review studies focusing on the surgical approach for CM patients with ISI on T2weighted MRI, there are similar studies regarding the surgical approach for all CM patients [2, 38-40]. In the study by Chen et al., a total of 25 nonrandomized controlled studies involving 1843 patients were included [2]. Similarly, the anterior approach was found to be associated with better postoperative neurological outcomes than the posterior approach in CSM patients. However, several studies, including one meta-analysis [40], have suggested that current studies are unable to demonstrate clinically significant differences between anterior and posterior approaches. Our study showed a $12 \%$ higher recovery rate following the anterior approach than following the posterior approach. Since ISI often indicates severe compression, the anterior approach is effective in releasing the compressed spinal cord in patients with ISI. Compared with the posterior approach, the anterior approach can decompress the spinal cord directly and allow substantial restoration of cervical lordosis. This may also explain why studies on surgical approach selection for all $\mathrm{CM}$ patients are controversialin terms of the patients with mild CM, both the anterior and posterior approach can provide sufficient space for a compressed spinal cord.

Surgical complications of CM include dysphagia, airway compromise, dysphonia, C5 nerve palsy, blood loss, and postoperative wound infection. For all $\mathrm{CM}$ patients (regardless of T2-weighted imaging findings), no significant differences in complication rates and revision rates have been observed in previous studies when comparing the anterior approach with the posterior approach [41-43]. Data for patients with ISI on T2weighted MRI are scarce, and the available studies did not report the incidence rate in detail. Sun et al. suggested that OPLL patients with ISI on T2-weighted MRI had more blood loss and a longer operative time than those without ISI [11]. This outcome may be because anterior exposure of the cervical spine involves more

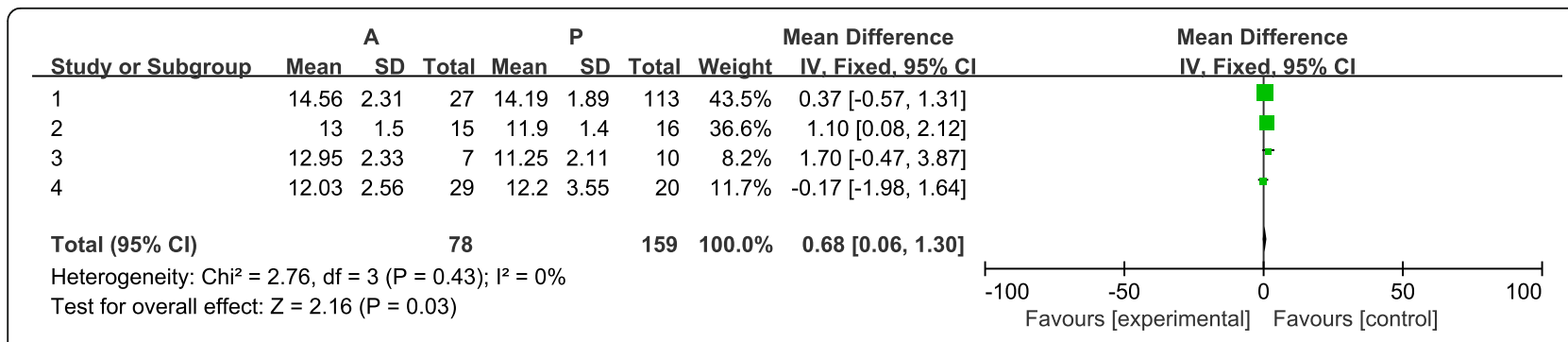

Fig. 3 Weighted mean difference in the postoperative JOA score between the anterior surgery group and the posterior surgery group 


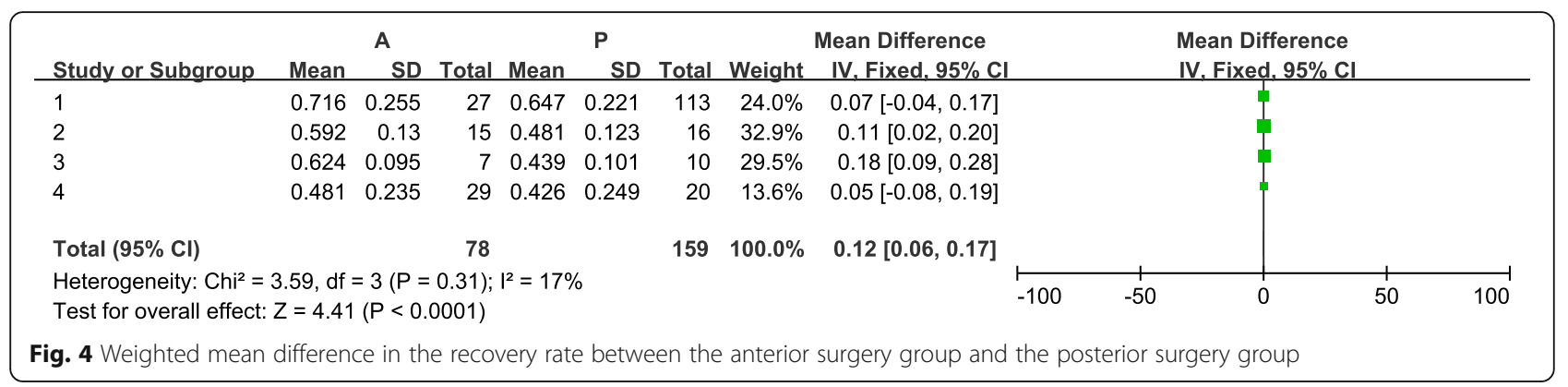

complex and potentially dangerous anatomy, especially for patients with ISI on T2-weighted MRI. However, more data are needed to draw a conclusion.

Our study has several limitations. First, the disparity in surgical interventions was not considered-i.e., ACCF vs. ACDF, laminectomy vs. laminoplasty-although postoperative outcomes have been suggested to be similar in previous studies [44, 45]. Second, most of our included studies were nonrandomized. Although the quality of the included studies did not seem to be poor based on an assessment with the NOS or the Cochrane Collaboration tool, more randomized controlled trials are needed due to the variety of procedures available and the spectrum of results. Third, as the CNKI contains only Chinese literature, the use of this database might have resulted in selection bias. Moreover, most studies commented sparsely about specific inclusion and exclusion criteria.

\section{Conclusion}

In conclusion, the anterior approach was associated with better postoperative neural function than the posterior approach in CM patients with ISI on T2-weighted MRI. The complication rate requires further investigation.

\section{Abbreviations \\ ACCF: Anterior cervical corpectomy decompression and fusion; ACDF: Anterior cervical discectomy and fusion; ACDR: Anterior cervical disc replacement; Cl: Confidence interval; CM: Cervical myelopathy; CNKI: Chinese National Knowledge Infrastructure; CSF: Cerebrospinal fluid; CSM: Cervical spondylotic myelopathy; HDF: Hybrid anterior decompression and fusion; ISI: Increased signal intensity; JOA: Japanese Orthopedic Association; MRI: Magnetic resonance imaging; OPLL: Ossification of the posterior longitudinal ligament; OR: Odds ratio; SD: Standard deviation; WMD: Weighted mean difference}

\section{Acknowledgements \\ Not applicable.}

\section{Authors' contributions}

$X Y$ and CF conducted the literature review and data collection. WYP and ZJG performed the data analysis. $\mathrm{HJH}$ and $\mathrm{XY}$ wrote the manuscript. All authors read and approved the final manuscript.

\section{Funding}

Not applicable.
Availability of data and materials

The datasets used and/or analyzed during the current study are available from the corresponding author on reasonable request.

Ethics approval and consent to participate

Not applicable.

\section{Consent for publication}

Not applicable.

\section{Competing interests}

The authors declare that they have no competing interests.

\section{Author details}

${ }^{1}$ Department of Surgery, Peking Union Medical College Hospital, Chinese Academy of Medical Science \& Peking Union Medical College, Beijing, China. ${ }^{2}$ Department of Orthopedics, Peking Union Medical College Hospital, Chinese Academy of Medical Science \& Peking Union Medical College, Beijing, China.

Received: 14 April 2019 Accepted: 8 July 2019

Published online: 18 July 2019

References

1. Kwon SY, Shin JJ, Lee JH, et al. Prognostic factors for surgical outcome in spinal cord injury associated with ossification of the posterior longitudinal ligament (OPLL). J Orthop Surg Res. 2015;10:94.

2. Chen Z, Liu B, Dong J, et al. A comparison of the anterior approach and the posterior approach in treating multilevel cervical myelopathy: a metaanalysis. Clin Spine Surg. 2017;30(2):65-76.

3. Zhang L, Chen J, Cao C, et al. Anterior versus posterior approach for the therapy of multilevel cervical spondylotic myelopathy: a meta-analysis and systematic review. Arch Orthop Trauma Surg. 2019;139(6):735-42.

4. Qin R, Chen X, Zhou P, et al. Anterior cervical corpectomy and fusion versus posterior laminoplasty for the treatment of oppressive myelopathy owing to cervical ossification of posterior longitudinal ligament: a meta-analysis. Eur Spine J. 2018;27(6):1375-87.

5. Mummaneni PV, Kaiser MG, Matz PG, et al. Preoperative patient selection with magnetic resonance imaging, computed tomography, and electroencephalography: does the test predict outcome after cervical surgery? J Neurosurg Spine. 2009;11(2):119-29.

6. Wright RW, Brand RA, Dunn W, et al. How to write a systematic review. Clin Orthop Relat Res. 2007;455:23-9.

7. Stang A. Critical evaluation of the Newcastle-Ottawa scale for the assessment of the quality of nonrandomized studies in meta-analyses. Eur J Epidemiol. 2010;25(9):603-5.

8. Higgins JP, Altman DG. Chapter 8: assessing risk of bias in included studies. In: Cochrane Handbook for Systematic Reviews of Interventions; 2011.

9. Hozo SP, Djulbegovic B, Hozo I. Estimating the mean and variance from the median, range, and the size of a sample. BMC Med Res Methodol. 2005;5:13.

10. Gu Y, Shi J, Cao P, et al. Clinical and imaging predictors of surgical outcome in multilevel cervical ossification of posterior longitudinal ligament: an analysis of 184 patients. PLoS One. 2015;10(9):e0136042.

11. Sun $Q, H u H$, Zhang $Y$, et al. Do intramedullary spinal cord changes in signal intensity on MRI affect surgical opportunity and approach for cervical myelopathy due to ossification of the posterior longitudinal ligament? Eur Spine J. 2011;20(9):1466-73. 
12. Liu H, Li Y, Chen Y, et al. Cervical curvature, spinal cord MRIT2 signal, and occupying ratio impact surgical approach selection in patients with ossification of the posterior longitudinal ligament. Eur Spine J. 2013;22(7):1480-8.

13. Linfeng W. Comparison of three different surgical approach for multilevel cervical spondylotic myelopathy by classification of quantifying MRI M T2 signal intensity ratio: Hebei Medical University; 2010. http://cdmd.cnki.com. cn/Article/CDMD-11919-2009139106.htm.

14. Hou Y, Liang L, Shi GD, et al. Comparing effects of cervical anterior approach and laminoplasty in surgical management of cervical ossification of posterior longitudinal ligament by a prospective nonrandomized controlled study. Orthop Traumatol Surg Res. 2017;103(5):733-40.

15. Salem HMI, Salem KMI, Burget F, et al. Cervical spondylotic myelopathy: the prediction of outcome following surgical intervention in 93 patients using T1- and T2-weighted MRI scans. Eur Spine J. 2015;24(12):2930-5.

16. Suri A, Chabbra RP, Mehta VS, et al. Effect of intramedullary signal changes on the surgical outcome of patients with cervical spondylotic myelopathy. Spine J. 2003;3(1):33-45.

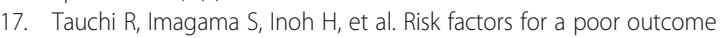
following surgical treatment of cervical spondylotic amyotrophy: a multicenter study. Eur Spine J. 2013;22(1):156-61.

18. Uchida K, Nakajima H, Sato R, et al. Multivariate analysis of the neurological outcome of surgery for cervical compressive myelopathy. J Orthop Sci. 2005;10(6):564-73.

19. Takahashi M, Sakamoto Y, Miyawaki M, et al. Increased MR signal intensity secondary to chronic cervical cord compression. Neuroradiology. 1987;29(6):550-6.

20. Vedantam A, Rajshekhar V. Does the type of T2-weighted hyperintensity influence surgical outcome in patients with cervical spondylotic myelopathy? a review. Eur Spine J. 2013;22(1):96-106.

21. Lee J, Koyanagi I, Hida K, et al. Spinal cord edema: unusual magnetic resonance imaging findings in cervical spondylosis. J Neurosurg. 2003;99(1 Suppl):8-13.

22. Bommireddy R, Kamat A, Smith ET, et al. Magnetic resonance image findings in the early post-operative period after anterior cervical discectomy. Eur Spine J. 2007;16(1):27-31.

23. Guppy KH, Hawk M, Chakrabarti I, et al. The use of flexion-extension magnetic resonance imaging for evaluating signal intensity changes of the cervical spinal cord. J Neurosurg Spine. 2009;10(4):366-73.

24. Henderson FC, Geddes JF, Vaccaro AR, et al. Stretch-associated injury in cervical spondylotic myelopathy: new concept and review. Neurosurgery. 2005;56(5):1101-13 discussion 1101-1113.

25. Zhang L, Zeitoun D, Rangel A, et al. Preoperative evaluation of the cervical spondylotic myelopathy with flexion-extension magnetic resonance imaging: about a prospective study of fifty patients. Spine (Phila Pa 1976). 2011;36(17):E1134-9.

26. Yagi M, Ninomiya $\mathrm{K}$, Kihara $\mathrm{M}$, et al. Long-term surgical outcome and risk factors in patients with cervical myelopathy and a change in signal intensity of intramedullary spinal cord on magnetic resonance imaging. J Neurosurg Spine. 2010;12(1):59-65.

27. Avadhani A, Rajasekaran S, Shetty AP. Comparison of prognostic value of different MRI classifications of signal intensity change in cervical spondylotic myelopathy. Spine J. 2010;10(6):475-85.

28. Fernandez de Rota JJ, Meschian S, Fernandez de Rota A, et al. Cervical spondylotic myelopathy due to chronic compression: the role of signal intensity changes in magnetic resonance images. J Neurosurg Spine. 2007;6(1):17-22.

29. Wada E, Yonenobu K, Suzuki S, et al. Can intramedullary signal change on magnetic resonance imaging predict surgical outcome in cervical spondylotic myelopathy? Spine (Phila Pa 1976). 1999;24(5):455-61 discussion 462.

30. Ahn JS, Lee JK, Kim BK. Prognostic factors that affect the surgical outcome of the laminoplasty in cervical spondylotic myelopathy. Clin Orthop Surg. 2010;2(2):98-104.

31. Chen CJ, Lyu RK, Lee ST, et al. Intramedullary high signal intensity on T2-weighted MR images in cervical spondylotic myelopathy: prediction of prognosis with type of intensity. Radiology. 2001;221(3):789-94.

32. Yukawa Y, Kato F, Yoshihara H, et al. MR T2 image classification in cervical compression myelopathy: predictor of surgical outcomes. Spine (Phila Pa 1976). 2007;32(15):1675-8 discussion 1679.

33. Vedantam A, Jonathan A, Rajshekhar V. Association of magnetic resonance imaging signal changes and outcome prediction after surgery for cervical spondylotic myelopathy. J Neurosurg Spine. 2011;15(6):660-6.
34. Shin JJ, Jin BH, Kim KS, et al. Intramedullary high signal intensity and neurological status as prognostic factors in cervical spondylotic myelopathy. Acta Neurochir. 2010;152(10):1687-94.

35. Ito $\mathrm{K}$, Imagama S, Ito $\mathrm{K}$, et al. MRI signal intensity classification in cervical ossification of the posterior longitudinal ligament: predictor of surgical outcomes. Spine (Phila Pa 1976). 2017;42(2):E98-e103.

36. Yukawa Y, Kato F, Ito K, et al. Postoperative changes in spinal cord signal intensity in patients with cervical compression myelopathy: comparison between preoperative and postoperative magnetic resonance images. J Neurosurg Spine. 2008;8(6):524-8.

37. Nouri A, Martin AR, Nater A, et al. Influence of magnetic resonance imaging features on surgical decision-making in degenerative cervical myelopathy: results from a global survey of AOSpine International members. World Neurosurg. 2017;105:864-74.

38. Zhu B, Xu Y, Liu X, et al. Anterior approach versus posterior approach for the treatment of multilevel cervical spondylotic myelopathy: a systemic review and meta-analysis. Eur Spine J. 2013;22(7):1583-93.

39. Cunningham MR, Hershman S, Bendo J. Systematic review of cohort studies comparing surgical treatments for cervical spondylotic myelopathy. Spine (Phila Pa 1976). 2010;35(5):537-43.

40. Lawrence BD, Jacobs WB, Norvell DC, et al. Anterior versus posterior approach for treatment of cervical spondylotic myelopathy: a systematic review. Spine (Phila Pa 1976). 2013;38(22 Suppl 1):S173-82.

41. Woods Bl, Hohl J, Lee J, et al. Laminoplasty versus laminectomy and fusion for multilevel cervical spondylotic myelopathy. Clin Orthop Relat Res. 2011:469(3):688-95.

42. Heller JG, Edwards CC 2nd, Murakami H, et al. Laminoplasty versus laminectomy and fusion for multilevel cervical myelopathy: an independent matched cohort analysis. Spine (Phila Pa 1976). 2001;26(12):1330-6.

43. Kato $\mathrm{S}$, Nouri $\mathrm{A}, \mathrm{Wu} \mathrm{D}$, et al. Comparison of anterior and posterior surgery for degenerative cervical myelopathy: an MRI-based propensity-scorematched analysis using data from the prospective multicenter AOSpine CSM North America and international studies. J Bone Joint Surg (Am Vol). 2017:99(12):1013-21.

44. Fehlings MG, Santaguida C, Tetreault L, et al. Laminectomy and fusion versus laminoplasty for the treatment of degenerative cervical myelopathy: results from the AOSpine North America and International prospective multicenter studies. Spine J. 2017;17(1):102-8.

45. Xiao SW, Jiang $H$, Yang $L J$, et al. Anterior cervical discectomy versus corpectomy for multilevel cervical spondylotic myelopathy: a meta-analysis. Eur Spine J. 2015;24(1):31-9.

\section{Publisher's Note}

Springer Nature remains neutral with regard to jurisdictional claims in published maps and institutional affiliations.

Ready to submit your research? Choose BMC and benefit from:

- fast, convenient online submission

- thorough peer review by experienced researchers in your field

- rapid publication on acceptance

- support for research data, including large and complex data types

- gold Open Access which fosters wider collaboration and increased citations

- maximum visibility for your research: over $100 \mathrm{M}$ website views per year

At BMC, research is always in progress.

Learn more biomedcentral.com/submissions 